\title{
Prevention of intraocular pressure rise following intravitreal injection
}

\section{Department of Ophthalmology, University of New South Wales, Prince of Wales Hospital, Randwick, Australia N Morlet $S$ H Young Correspondence to: Dr N Morlet, Department of Ophthalmology, University of NSW, Prince of Wales Hospital, High Street, Randwick NSW 2031, Australia. \\ Accepted for publication 18 May 1993}

Figure 1 The mercury bag resting on the eye before intravitreal injection.

\author{
Nigel Morlet, Stephanie H Young
}

high dose ganciclovir, which we have found to be more effective than intravenous treatment, without the associated systemic side effects. ${ }^{4}$

We noticed that following an intravitreal injection patients often complained of temporary but complete loss of vision in that eye. We undertook this study to demonstrate the effect of intravitreal injection on the intraocular pressure (IOP) and the effect of prior decompression of the globe with a mercury bag on the post-injection IOP.

\section{Methods}

All the subjects in this study were receiving intravitreal ganciclovir injections for CMV retinitis. The IOP of six eyes from four patients was measured before and immediately after an intraocular injection of ganciclovir, $2 \mathrm{mg}$ in $0.1 \mathrm{ml}$, on four occasions. On four other occasions, before the injection the eye was decompressed by applying a $30 \mathrm{~mm} \mathrm{Hg}$ pressure for 15 minutes. Additional IOP measurements were obtained from four other patients unable to complete the crossover procedure: four measurements were with ocular decompression (three patients) and four were without (one patient).

The decompression was performed using a mercury bag (Mirosurgical Technology Inc, Kirkland WA, USA) resting on the eye of the recumbent patient (see Fig 1). A Tono-pen XL was used to measure the IOPs and was calibrated before each measurement session according to the manufacturer's instructions. All the measurements were taken from recumbent patients before and after the placement of the mercury bag.

Only those measurements displaying $<5 \%$ variance on the readout were recorded. For those measurements taken after the injection only the first reading was used because the IOP fell quickly over the first 1 or 2 minutes and the Tono-pen takes 10 to 20 seconds to record the pressure readings. The variance of all the postinjection recordings was still $<5 \%$.

Before the injection, a drop of cocaine $4 \%$ with adrenaline $1 / 100000$ was administered every 5 minutes into the conjunctival sac for 30 minutes. A drop of $5 \%$ povidone iodine was given just before placing the mercury bag, or 5 minutes before the injection without decompression.

The injection was placed $4 \mathrm{~mm}$ from the limbus through the inferotemporal pars plana using a 30 gauge needle directed towards the mid-vitreal cavity. The bevel of the needle was directed away from the retina. After the needle was inserted up to the hub the ganciclovir was injected slowly over 5 seconds.

Immediately after the needle was withdrawn, measurements of the IOP began. Following the injection and measurements the patient was 
questioned about discomfort from the procedure, and the injection site was observed for the formation of a subconjunctival bleb. Chloramphenicol $1 \%$ ointment was administered and the eye was patched for 3 hours.

For statistical analysis means, differences in means, and their confidence intervals were calculated using the CIA software. ${ }^{5} \mathrm{~A} p$ value less than 0.05 from the paired $t$ test was considered significant.

\section{Results}

Twenty eight measurements using the mercury bag and 28 measurements without it were taken. The mean pre and post-injection IOPs, and the mean differences in the pressures are shown in Table 1. The IOP before injection was lowered by cocaine and adrenaline anaesthetic drops. In all cases there was a significant pressure rise following the intravitreal injection. Use of the mercury bag significantly reduced the postinjection pressure from a mean of $44.5 \mathrm{~mm} \mathrm{Hg}$ to $20.6 \mathrm{~mm} \mathrm{Hg}(\mathrm{p}<0.001)$.

Following the 15 minutes of decompression, the IOP was unrecordable $(<2 \mathrm{~mm} \mathrm{Hg}$ ) in five of the six eyes and they then demonstrated a significant reduction in the post-injection pressure rise. The patient who failed to demonstrate any benefit from the mercury bag decompression had a small orbital aperture and deeply set eyes. In this case the mercury bag was supported by the orbital rim without applying much pressure on the globe itself. We found that this patient had a large amount of reflux of the injection fluid post-injection, associated with a wide range of IOPs.

Without ocular decompression before injection, all patients complained of temporary loss of vision that did not return until the pressure was observed to fall below $30-35 \mathrm{~mm} \mathrm{Hg}$. There was also more discomfort associated with the insertion of the needle and the injection, and reflux of some of the injection fluid was frequently observed.

The use of the mercury bag before intravitreal injection was not shown to adversely affect the visual outcomes for the patients in this study.

\section{Discussion}

A significant decrease in the IOP with the use of

Table 1 The effect of ocular decompression on the intraocular pressure following an intravitreal injection of $0.1 \mathrm{ml}$ ganciclovir

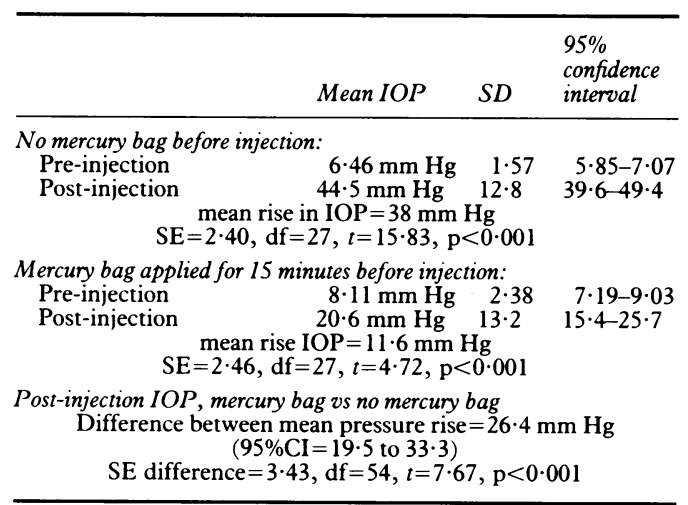

direct ocular compression for 10 minutes following a retro or parabulbar anaesthetic injection was described in the studies by Jay et $a l^{6}$ and Ropo et al. ${ }^{7}$ The practice of ocular decompression after local anaesthesia before intraocular surgery is now standard in most centres.

The results demonstrate clearly a reduction in post-injection IOP rise with the use of a mercury bag to decompress the globe and orbit before injection. This technique makes the procedure less distressing for the patient and at the same time ensures the delivery of the total volume of the injection fluid into the vitreous cavity.

The Tono-pen XL was used to measure the IOPs in this study because the patients needed to be recumbent for the injections and the mercury bag decompression. This tonometer was calibrated in cadaveric eyes and against the Goldmann tonometer in clinical studies and found to be accurate across the range 10 to $30 \mathrm{~mm} \mathrm{Hg} .^{8-11}$ Above $30 \mathrm{~mm} \mathrm{Hg}$ it tends to underread the IOP and below $10 \mathrm{~mm} \mathrm{Hg}$ it tends to overread the IOP, so any such bias would have reduced the mean differences of our measurements. The Tono-pen was also reported to have some variability between units early in its production ${ }^{7}$ but there have not been any reports of this with the XL model. Although we did not calibrate our Tono-pen against a Goldmann tonometer, the internal calibration of the Tono-pen ensured the consistency of our readings. The measurement bias of the instrument at high and low pressures and the lack of calibration data with a Goldmann tonometer may not give accurate absolute pressure values, however this does not invalidate the relative reduction in the post-injection pressure we found with ocular decompression.

We would recommend this technique to those performing intravitreal injections as is now our clinical practice.

Presented at the 24th Annual Scientific Congress of the Royal Australian College of Ophthalmologists, Sydney, November 1992. The St George Hospital eye clinic kindly provided the Tono-pen on loan for the duration of the study. The clinical photograph was taken by the Medical Illustration Unit of the UNSW, Prince of Wales Hospital.

1 Cantrill HL, Henry K, Melroe NH, Knobloch WH, Ramsay RC, Balfour HH Treatment of cytomegalovirus retinitis $\mathrm{RC}$, Balfour HH. Treatment of cytomegalovirus retinitis with intravitreal gancicl

2 Heineman MH. Long-term intravitreal ganciclovir therapy for cytomegalovirus retinopathy. Arch Ophthalmol 1989; 107: 1767-72.

3 Cochereau-Massin I, Lehoang P, Lautier-Frau M, Zazoun L, Marcel P, Robinet $M$, et al. Efficacy and tolerance of intravitreal ganciclovirus retinitis in acquired immune deficiency syndrome. Ophthalmology 1991; 98: 1348-55.

4 Young SH, Morlet N, Heery S, Hollows FC, Coroneo MT High dose intravitreal ganciclovir in the treatment of cyclomegalovirus retinitis. Med f A ust 1992; 157: 370-3.

5 Gardner MJ, Altman DG. Statistics with confidence. London: BMJ Books 1989.

6 Jay WM, Carter H, Williams B, Green K. Effect of applying the Honan intraocular pressure reducer before cataract surgery. Am f Ophthalmol 1985; 100: 523-7.

7 Ropo A, Russuvaara P, Paloheimo M, Manunuksela E-L, Nikki P. Effect of ocular compression (Autopressor) on the intraocular pressure in periocular anaesthesia. Acta Ophthalmol 1990; 68: 227-9.

8 Minkler DS, Baerveldt G, Heuer DK, Quillen-Thomas B Walonker AF, Weiner J. Clinical evaluation of the Oculab Tono-pen. Am f Ophthalmol 1987; 104: 168-73.

9 Kao SF, Lichter PR, Bergstrom TJ, Rowe S, Musch DC. Clinical comparison of the Oculab Tono-pen to the Goldmann applanation tonometer. Ophthalmology 1987; 94: mann appl.

10 Frenkel RP, Hong YJ, Shin DH. Comparison of the Tono-pen to the Goldmann applanation tonometer. Arch Ophthalmol
1988; 106: 750-3.

11 Boothe WA, Lee DA, Panek WC, Pettit TH. The Tonopen - a manometric and clinical study. Arch Ophthalmol 1988; 106: manome 